\title{
New Mesozoic research inspired by the life and work of Dale A. Russell
}

\author{
Guest Editors \\ Jordan C. Mallon \\ Canadian Museum of Nature, Ottawa, Ontario, Canada \\ Philip J. Currie \\ University of Alberta, Edmonton, Alberta, Canada \\ Kathlyn M. Stewart \\ Canadian Museum of Nature, Ottawa, Ontario, Canada
}

